\title{
NOWE STANOWISKO DIPLOSCHISTES MUSCORUM (SCOP.) R. SANT. NA NIZINIE WIELKOPOLSKO-KUJAWSKIEJ
}

\author{
DARIA ZARABSKA-BOŻEJEWICZ \\ Instytut Środowiska Rolniczego i Leśnego PAN, \\ ul. Bukowska 19, 60-809 Poznań \\ e-mail: zardaria@wp.pl
}

\begin{abstract}
Diploschistes muscorum (Scop.) R. Sant. has been found in the southern part of the Wielkopolsko-Kujawska Lowland. So far, in western and central Poland the species has been reported in few localities.
\end{abstract}

Keywords: Diploschistes muscorum, distribution, lichens, rare species, west-central Poland

Nizina Wielkopolsko-Kujawska, w granicach wskazanych przez Latowskiego (2004), należy pod względem lichenologicznym do słabiej poznanych obszarów kraju. Większość opracowań opisujących występowanie porostów na tym terenie powstała w II połowie XX w. (Zarabska 2011). Jednak dane w nich prezentowane można już uznać za historyczne. Wprawdzie w okresie ostatnich kilkunastu lat pojawiły się prace poświęcone grzybom zlichenizowanym tego regionu (Gruszka 2010; Zarabska 2011; Lipnicki, Grochowski 2011, 2012; Lipnicki i in. 2012; Grochowski 2012, 2015, 2016; Kubiak, Biedunkiewicz 2015; Szczepańska, Grochowski 2015; Grochowski, Szczepańska 2016), jednakże stopień rozpoznania lichenobioty Wielkopolski jest ciągle daleki od zadowalającego. W związku z tym utrudnione jest m.in. określanie częstości występowania tam porostów. Na obecnym etapie znajomości zagadnienia bardziej pewne wydaje się wyróżnianie jako rzadkich taksonów na Nizinie Wielkopolsko-Kujawskiej tych, które również nie są częstym składnikiem bioty w innych częściach kraju. Porosty takie reprezentuje słojecznica mchowa Diploschistes muscorum (Scop.) R. Sant. Jej kolejne stanowisko wykryto w 2016 r. podczas badań terenowych w Baranowie koło Kępna (Wysoczyzna Wieruszowska). W niniejszej pracy przedstawiono krótką charakterystykę gatunku wraz z danymi na temat jego rozmieszczenia w środkowozachodniej części Polski.

Porost ten charakteryzuje się brodawkowato-areolkowaną plechą o popielato-, żółtawo- lub ciemnoszarym kolorze. Owocniki, których wielkość nie przekracza zwykle $1 \mathrm{~mm}$ średnicy, mają wgłębione, szarobrunatne tarczki (z delikatnym przyprószeniem lub nagie), początkowo zasłonięte brzeżkiem. Zarodniki 
są wielokomórkowe, murkowato podzielone, o wielkości 20-30 $\mu \mathrm{m} \times 9-15 \mu \mathrm{m}$ i mają kształt wrzecionowato-elipsoidalny (Nowak, Tobolewki 1975).

Na początkowym etapie swojego rozwoju słojecznica mchowa pasożytuje na łuskach chrobotków Cladonia, szczególnie z grupy C. pyxidata (Wirth 1995; Kukwa, Kowalewska 2007) i tworzy aposymbiotyczny związek z fykobiontem gospodarza - Trebouxia irregularis Hildr. \& Ahm (Friedl 1987; Czarnota 2009; Fernández-Brime i in. 2013). Dopiero po związaniu z kompatybilnym fotosyntetyzującym partnerem T. showmanii (Hildr. \& Ahm.) Gärtner, D. muscorum staje się niezależny i jest zdolny do kolonizowania innych substratów, takich jak gleba, mszaki i szczątki roślinne (Nowak, Tobolewski 1975). Słojecznica mchowa zdaje się szczególnie związana z podłożami zasobnymi w węglan wapnia (Nowak 1967; Nowak, Tobolewski 1975; Wirth 1995; Ceynowa-Giełdon 2001; Wieczorek, Schiefelbein 2013). Nowak (1967) wyróżnia D. muscorum jako typowy składnik wapieniolubnej lichenobioty na Wyżynie Krakowsko-Częstochowskiej.

Słojecznica mchowa preferuje miejsca suche i dobrze doświetlone (Nowak, Tobolewski 1975). Odnotowano wiele jej stwierdzeń w murawach kserotermicznych i psammofilnych (Glanc 1964; Zielińska 1967; Filipek 1974; Cieśliński 1986, 1997, 2003; Czyżewska 1986, 1992; Cieśliński, Tobolewski 1988; Fałtynowicz 1991; Ceynowa-Giełdon, Glazik 1994; Lipnicki, Grochowski 2011; Wieczorek, Schiefelbein 2013). Doliny rzeczne mogą być stosunkowo bogatymi skupieniami zbiorowisk kserotermicznych (Filipek 1974; Czyżewska 1986; Ceynowa-Giełdon, Glazik 1994), stąd gatunek jest często podawany z terenów położonych w sąsiedztwie rzek, np. Warty i Odry (Filipek 1974; Czyżewska 1986; Fałtynowicz 1991), Wisły (Ceynowa-Giełdon, Glazik 1994) oraz Drwęcy (Rutkowski, Słowik 1999).

Niehierarchiczne zbiorowisko z D. muscorum opisuje Zielińska (1967) w pracy poświęconej porostom Puszczy Kampinoskiej. Fitocenozy takie inicjują tam proces zarastania piasków wydmowych. W serii sukcesyjnej są wypierane przez murawę szczotlichową Corynephoretum canescentis cladonietosum lub (rzadziej) zbiorowisko psammofilne zbliżone do Festuceto-Thymetum serpylli (Zielińska l.c.). Według cytowanej autorki zbiorowisko ze słojecznicą mchową jest układem pionierskim, natomiast udział kserotermicznych mchów i porostów w płatach zwiększa się w nim w miarę pękania i kruszenia, a następnie wywiewania przez wiatr plech słojecznicy. Czyżewska (1992) wskazuje, że $D$. muscorum (wraz z innymi ciepłolubnymi porostami) najczęściej jest notowana $\mathrm{w}$ fitocenozach subkontynentalnej odmiany murawy szczotlichowej, opisanej w randze podzespołu Spergulo morisonii-Corynephoretum canescentis thymetosum serpyllii Czyżewska 1992.

Na nowo odkrytym stanowisku w Baranowie k. Kępna słojecznica mchowa występuje w murawie napiaskowej. Wśród zajmowanych przez omawiany porost podłoży znalazły się łuski plechy pierwotnej gatunków z rodzaju Cladonia, 
szczątki roślinne oraz gleba. Gatunki towarzyszące to: Cladonia cervicornis subsp. verticillata (Hoffm.) Ahti, C. furcata (Huds.) Schrad., C. pyxidata (L.) Hoffm., C. subulata (L.) Weber ex F.H. Wigg. i Peltigera didactyla (With.) J.R. Laundon.

W literaturze przedmiotu sygnalizuje się wycofywanie D. muscorum z terenów wcześniej zajmowanych (Glanc 1998; Matwiejuk 2016), np. w wyniku procesów sukcesyjnych zachodzących w murawach czy na pobrzeżach młodników sosnowych. Siedliska powstałe wskutek działalności człowieka mogą natomiast sprzyjać ekspansji porostu poza główne ośrodki jego występowania w kraju (Cieśliński 2003). Przykładem mogą być stwierdzenia słojecznicy mchowej znane z terenów kolejowych i ich sąsiedztwa (Dziabaszewski 1959, 1962; Czyżewska 1992; Fałtynowicz 1991; Ceynowa-Gełdon 2001; Adamska, Deptuła 2015) oraz żwirowni (Filipek 1974; Ceynowa-Giełdon 2001; Cieśliński 2003; Lipnicki i in. 2006; Lipnicki, Grochowski 2011; Adamska, Deptuła 2015). Zdaniem Ceynowej-Giełdon (2001) rozprzestrzenianiu gatunku sprzyja podłoże zasobne w węglan wapnia (np. wapienny gruz, cement lub zaprawa murarska). W Białymstoku porost ma jedyne swoje stanowisko na cmentarzu żydowskim, gdzie zasiedla warstwę humusu i mszaków rosnących na kamiennych i betonowych nagrobkach (Matwiejuk 2007, 2008). Dzięki zdolności akumulacji wysokich ilości metali bez szkody dla swoich funkcji życiowych słojecznica mchowa wskazywana jest również jako hiperakumulator cynku (Szarek-Łukaszewska, Grodzińska 2008; Bielczyk 2012). Jej notowania z podłoży bogatych w metale ciężkie $(\mathrm{Zn}, \mathrm{Pb})$ pochodzą z terenów dawniej objętych działalnością górniczą i metalurgiczną w południowej Polsce (Szarek-Łukaszewska, Grodzińska 2008; Bielczyk i in. 2009; Kowolik i in. 2010; Bielczyk 2012).

D. muscorum wydaje się szeroko rozpowszechniony na świecie (Purvis i in. 1992). Fałtynowicz (1991) wymienia go wśród gatunków kserokontynentalnych, charakterystycznych dla ciepłych i suchych regionów Holarktyki. W Polsce notowania słojecznicy mchowej znane są głównie z wyżynnej, południowej części kraju, na niżu jest natomiast rzadko stwierdzana (Nowak, Tobolewski 1975; Fałtynowicz 2000, 2003; Lipnicki, Grochowski 2011). Zaprezentowane w pracy Lipnickiego i Grochowskiego (2011) zestawienie stanowisk porostu, zlokalizowanych do tej pory w północnej i środkowej Polsce, można uzupełnić o ostatnie doniesienia o występowaniu słojecznicy mchowej na wyspie Wolin (Wieczorek, Łysko 2012; Wieczorek, Schiefelbein 2013) i w okolicach Torunia (Adamska, Deptuła 2015).

Jedną z pierwszych wzmianek odnoszących się do stanu poznania rozmieszczenia słojecznicy mchowej na Nizinie Wielkopolsko-Kujawskiej znaleźć można w pracy Krawca (1936). Autor wymienia D. muscorum wśród gatunków, które w związku z rzadkością notowań w Wielkopolsce wymagają poświęcenia większej uwagi i prowadzenia dalszych dokładniejszych badań. Stanowiska porostu, położone w zachodniej części regionu, znane są z okolic miejscowości: Czarnów, 
Tursk, Wędrzyn i Owczary (Hillmann, Grummann 1957), uzupełnione o późniejsze stwierdzenia przy południowej granicy rezerwatu „Słońsk” - przy przystanku PKP Czarnów (Lipnicki 1992) i w okolicach Pamięcina - niedaleko Kostrzyna nad Odrą i Słubic (Filipek 1974; Lipnicki, Grochowski 2011). Kolejne obserwacje pochodzą z Promna, leżącego niedaleko Poznania; słojecznica porastała tam plechy porostów z rodzaju Cladonia w miejscach silnie nasłonecznionych w zagajniku sosnowym blisko stacji kolejowej (Dziabaszewski 1959, 1962). Bardzo liczne plechy, zajmujące dużą przestrzeń na suchej, słonecznej, piaszczystej polanie, znaleziono także w Szreniawie koło Poznania (Dziabaszewski 1962). W latach 60. XX w. porost podano z terenu Nadleśnictwa Zielonka; jego plechy zaobserwowano w miejscu nasłonecznionym na skraju młodnika sosnowego (Glanc 1967). Nie udało się jednak potwierdzić występowania D. muscorum w Puszczy Zielonce podczas badań prowadzonych 30 lat później (Glanc 1998). Z północnych obrzeży regionu pochodzą doniesienia o notowaniu gatunku w murawach w okolicach Łupowa niedaleko Gorzowa Wlkp. (Filipek 1974). Stanowiska wysunięte najdalej na wschód regionu znane są z Kujaw (Czyżewska 1992; Ceynowa-Giełdon 2001); większość z nich opisano z rozległych terenów wydmowych położonych na południe od Torunia. Jedne $\mathrm{z}$ ostatnich stwierdzeń obejmują obserwacje słojecznicy mchowej na glebie w wyrobisku żwirowym w Drezdenku (Lipniki i in. 2006; Lipnicki, Grochowski 2011).

Wydaje się, iż stanowisko D. muscorum w Baranowie należy traktować raczej jako kolejny punkt zlokalizowany na obrzeżach obszarów gromadnego występowania gatunku na południu kraju (por. Fałtynowicz 2003) aniżeli oderwaną lokalizację na terenie Niziny Wielkopolsko-Kujawskiej. Na Wyżnie Wieluńskiej, sąsiadującej od południowego wschodu z Wysoczyzną Wieruszowską (Kondracki 2009), słojecznica mchowa ma przynajmniej kilka stwierdzeń (Nowak 1967; Czyżewska 1986). Jej obecność w tym regionie wiązano z dostępnością podłoży skalnych mających znaczenie siedliskowe dla porostów kalcyfilnych (Nowak 1967). Wysunięte najbardziej na północ, na obszarze Wyżyny Wieluńskiej stanowisko D. muscorum w okolicach Góry św. Genowefy koło Działoszyna, podane przez Nowaka (1967) i opisaną w niniejszym artykule lokalizację na Wysoczyźnie Wieruszowskiej dzieli około $60 \mathrm{~km}$.

Stanowisko - [CE36] - N 5116’24.24”, E 18¹'32.16”, Nizina Południowowielkopolska, Wysoczyzna Wieruszowska, Baranów k. Kępna - północno-wschodnia część miejscowości, na szczątkach roślinnych i łuskach plechy pierwotnej gatunków z rodzaju Cladonia oraz glebie, 25.06.2016 r., leg. D. Zarabska-Bożejewicz.

\section{Podziękowanie}

Składam serdeczne podziękowania GDDKiA, Oddział w Poznaniu za wyrażenie zgody na opublikowanie informacji o notowaniu słojecznicy mchowej 
w Baranowie. Dziękuję dr. Stanisławowi R os a dzińs kie mu za udzielone wskazówki w zakresie analizy danych fitosocjologicznych. Dziękuję mgr. Aleksandrowi Dę m b iń s k i e m u (Zbiory Przyrodnicze Wydziału Biologii UAM) za pomoc przy tłumaczeniu niemieckich nazw miejscowości podczas ustalania lokalizacji stanowisk D. muscorum na terenie Niziny Wielkopolsko-Kujawskiej.

\section{LITERATURA}

Adamska E., Deptuła M. (2015): Materials for biota of lichens and lichenicolous fungi in the military area near Toruń (Poland). Ecol. Quest., 21: 45-53.

Bielczyk U. (2012): Lichens of zinc-lead post-mining areas in the Olkusz region - state of preservation, threats and needs for protection. [W:] Lipnicki L. (red.). Lichen protection - protected lichen species: 119-128. Sonar Literacki. Gorzów Wlkp.

Bielczyk U., Jędrzejczyk-Korycińska M., Kiszka J. (2009): Lichens of abandoned zinc-lead mines. Acta Mycol., 44(2): 139-149.

Ceynowa-Giełdon M. (2001): Kalcyfilne porosty naziemne na Kujawach. Ss. 43. Wyd. Uniw. Mikołaja Kopernika. Toruń.

Ceynowa-Giełdon M., Glazik N. (1994): Rzadkie porosty kserokontynentalne na obszarze Dolnej Wisły. Fragm. Flor. Geobot., Ser. Polonica, 1: 41-47.

Cieśliński S. (1986): Porosty muraw kserotermicznych na kemach w północnej części Równiny Bielskiej. Fragm. Flor. Geobot., 29(3-4): 435-449.

Cieśliński S. (1997): Porosty. [W:] Zielony R. (red.). Lasy Puszczy Kozienickiej: 106-121. Wyd. SGGW. Warszawa.

Cieśliński S. (2003): Atlas rozmieszczenia porostów (Lichenes) w Polsce północno-wschodniej. Phytocoenosis, 15 (N.S.), Suppl. Cartographiae Geobotan., 15: 1-426.

Cieśliński S., Tobolewski Z. (1988): Porosty (Lichenes) Puszczy Białowieskiej i jej zachodniego przedpola. Phytocoenosis, 1 (N.S.), Suppl. Cartographiae Geobotan., 1: 3-216.

Czarnota P. (2009): Symbiozy porostowe w świetle interakcji pomiędzy grzybami i fotobiontami. Kosmos, 58(1-2): 229-248.

Czyżewska K. (1986): Murawy piaskowe w Załęczańskim Parku Krajobrazowym (Wyżyna Wieluńska). Acta Univ. Lodz., Fol. Sozol., 2: 471-522.

Czyżewska K. (1992): Syntaksonomia śródlądowych muraw napiaskowych. Monogr. Bot., 74: $1-174$.

Dziabaszewski B. (1959): Z badań nad porostami Promna pod Poznaniem. Przyr. Polski Zach., 3: 191-192.

Dziabaszewski B. (1962): Porosty okolic Poznania na tle porostów Wielkopolski. Pr. Kom. Biol. PTPN, 22(4): 1-159.

Fałtynowicz W. (1991): Porosty Pomorza Zachodniego. Studium ekologiczno-geograficzne. Ss. 187. Uniw. Gdański. Gdańsk.

Fałtynowicz W. (2000): Diploschistes muscorum i inne interesujące gatunki porostów w Borach Tucholskich (północna Polska). Acta Bot. Cassub., 1: 143-145.

Fałtynowicz W. (2003): The lichens, lichenicolous and allied fungi of Poland. An annotated checklist. - Krytyczna lista porostów i grzybów naporostowych Polski. Ss. 435. W. Szafer Inst. of Bot., Pol. Acad. of Sci. Kraków.

Fernández-Brime S., Llimona X., Lutzoni F., Gaya E. (2013): Phylogenetic study of Diploschistes (lichen-forming Ascomycota: Ostropales: Graphidaceae), based on morphological, chemical and molecular data. Taxon, 62(2): 267-280.

Filipek M. (1974): Murawy kserotermiczne regionu dolnej Odry i Warty. Pr. Kom. Biol. PTPN, 38: $1-109$. 
Friedl T. (1987): Thallus development and phycobionts of the parasitic lichen Diploschistes muscorum. Lichenologist, 19(2): 183-191.

Glanc K. (1964): Lecidea decipiens (Ehrh.) Ach. i inne interesujące gatunki porostów w murawach kserotermicznych północno-zachodniej Polski. Fragm. Flor. Geobot., 10(2): 263-267.

Glanc K. (1967): Flora porostów i jej udział w zespołach leśnych Nadleśnictwa Doświadczalnego Zielonka pod Poznaniem. Roczn. WSR Pozn., 34(8): 137-182.

Glanc K. (1998): Zanikanie porostów na obszarze Puszczy Zielonka pod Poznaniem (Wielkopolska). [W:] Czyżewska K. (red.). Różnorodność biologiczna porostów: 71-79. Wyd. UŁ. Łódź.

Grochowski P. (2012): Secondary succession with the participation of protected species of lichens in the charred areas of the Forest Inspectorate of Lubsko. [W:] Lipnicki L. (red.). Lichen protection - protected lichen species: 205-212. Sonar Literacki. Gorzów Wlkp.

Grochowski P. (2015): Lichenobiota województwa lubuskiego na terenach obszarów Natura 2000. Ss. 200. Reg. Dyr. Ochr. Środ. Gorzów Wlkp.

Grochowski P. (2016). Lichenobiota. [W:] Grochowski P., Jerzak L. (red.). Pszczewski Park Krajobrazowy 30 lat: historia i przyroda: 72-95. Zesp. Parków Krajobrazowych Woj. Lubuskiego. Gorzów Wlkp.-Zielona Góra.

Grochowski P., Szczepańska K. (2016): Porosty Gryżyńskiego Parku Krajobrazowego. [W:] Maciantowicz M. (red.). Gryżyński Park Krajobrazowy 20 lat: monografia przyrodnicza: 100109. Zesp. Parków Krajobrazowych Województwa Lubuskiego. Gorzów Wlkp.-Zielona Góra.

Gruszka W. (2010): Zmiany bioty porostów rezerwatu „Dębina” koło Wągrowca. Bad. Fizjogr., R. I (B59): 173-183.

Hillmann J., Grummann V. (1957): Kryptogamenflora der Mark Brandenburg und angrenzender Gebiete. Band VIII: Flechten. Ss. 898. Gebrüder Borntraeger. Berlin-Nikolassee.

Kondracki J. (2009): Geografia regionalna Polski. Wyd. 3. Ss. 444. Wyd. Nauk. PWN. Warszawa.

Kowolik M., Szarek-Łukaszewska G., Jędrzejczyk-Korycińska M. (2010): Użytek ekologiczny „Pleszczotka górska” w cynkowo-ołowiowym terenie pogórniczym - potrzeba aktywnej ochrony. Chrońmy Przyr. Ojcz., 66(1): 35-38.

Krawiec F. (1936): Porosty. Wyd. Okręg. Kom. Ochr. Przyr. na Wlkp. i Pom., 6: 21-24.

Kubiak D., Biedunkiewicz A. (2015): Biota porostów rezerwatów przyrody uroczyska „Pępowo” (SW Wielkopolska). Acta Bot. Siles., 11: 129-140.

Kukwa M., Kowalewska A. (2007): New or interesting records of lichenicolous fungi from Poland V. Species mainly on Cladonia. Herzogia, 20: 199-207.

Latowski K. (2004): Charakterystyka fizjograficzna Wielkopolski. [W:] Chmiel J., Kasprowicz M. (red.). Flora i roślinność środkowej Wielkopolski: 10-24. Bogucki Wyd. Nauk. Poznań.

Lipnicki L. (1992): Porosty rezerwatu „Słońsk”. [W:] Agapow L. (red.). Flora i fauna rezerwatu przyrody „Słońsk”: 28-32. Wydz. Ochr. Środ. Urz. Woj. Gorzów Wlkp.

Lipnicki L., Grochowski P. (2011): Nowe stanowisko Diploschistes muscorum (Scop.) R. Sant. (zlichenizowane Ascomycota) w Polsce Zachodniej. Bad. Fizjogr., R. II (B60): 175-179.

Lipnicki L., Grochowski P. (2012): The lichens of "Mierkowskie Suche Bory" nature reserve. [W:] Lipnicki L. (red.). Lichen protection - protected lichen species: 151-161. Sonar Literacki. Gorzów Wlkp.

Lipnicki L., Grochowski P., Gruszka W. (2012): The protected and threatened lichens on the bark of Larix decidua in the selected localities in the middle part of Western Poland. [W:] Lipnicki L. (red.). Lichen protection - protected lichen species. 187-196. Sonar Literacki. Gorzów Wlkp.

Lipnicki L., Grochowski P., Łazarska M. (2006): Porosty (Lichenes). [W:] Lipnicki L. (red.). Przyroda gminy Drezdenko: 94-103. UMiG Drezdenko, Agencja Rekl.-Wydawn. Grzegorczyk. Drezdenko.

Matwiejuk A. (2007): Porosty Białegostoku. Analiza florystyczno-ekologiczna. Tom I. Ss. 143. Wyd. Ekon. i Środ. Białystok.

Matwiejuk A. (2008): Lichens of the Jewish cemetery in Białystok (north-eastern Poland). Bot. Steciana, 12: 111-116. 
Matwiejuk A. (2016): Występowanie porostów naziemnych w wybranych płatach różnych typów siedlisk w okolicach Zalewu Siemianówka w Dolinie Górnej Narwi. Leśn. Pr. Bad., 77(2): 94-103.

Nowak J. (1967): Porosty Wyżyny Wieluńskiej. Acta Mycol., 3: 209-242.

Nowak J., Tobolewski Z. (1975): Porosty polskie. Ss. 1177. PWN. Warszawa-Kraków.

Purvis O. W., Coppins B. J., Hawksworth D. L., James P. W., Moore D. M. (red.) (1992): The lichen flora of Great Britain and Ireland. Ss. 710. Natur. Hist. Publ. London.

Rutkowski P., Słowik J. (1999): Flora porostów doliny Drwęcy w okolicy Nowego Miasta Lubawskiego. Fragm. Flor. Geobot., Ser. Polonica, 6: 211-217.

Szarek-Łukaszewska G., Grodzińska K. (2008): Naturalna roślinność w rejonach starych zwałowisk odpadów po górnictwie rud $\mathrm{Zn}-\mathrm{Pb}$ w okolicy Bolesławia i Bukowna (region śląsko-krakowski; południowa Polska). Przegl. Geolog., 56(7): 528-531.

Szczepańska K., Grochowski P. (2015): Porosty. [W:] Pukacz A., Pełechaty M. (red.). Łagowsko-Sulęciński Park Krajobrazowy 30 lat: różnorodność ekologiczna i gatunkowa: 171-185. Zesp. Parków Krajobrazowych Woj. Lubuskiego. Gorzów Wlkp.

Wieczorek A., Łysko A. (2012): Lichen biota of the Wolin Island (Poland). Biodiv. Res. Conserv., 25: 83-89.

Wieczorek A., Schiefelbein U. (2013): Lichens of xerothermic grasslands in Western Pomerania (Poland). Plant Divers. Evol., 130(3-4): 295-302.

Wirth V. (1995): Die Flechten Baden-Württembergs. Ss. 1006. Verlag Eugen Ulmer. Stuttgart.

Zarabska D. (2011): Porosty w krajobrazie rolniczym Sandru Nowotomyskiego. Pr. dokt. ze Zbiorów Przyr. UAM. Poznań (mskr.).

Zielińska J. (1967): Porosty Puszczy Kampinoskiej. Monogr. Bot., 24: 1-130.

\section{THE NEW LOCALITY OF DIPLOSCHISTES MUSCORUM (SCOP.) R. SANT. IN THE WIELKOPOLSKO-KUJAWSKA LOWLAND}

\section{Sum mary}

Diploschistes muscorum (Scop.) R. Sant. initiates its development as a parasite on Cladonia squamules, and later it forms an independent and grows on mosses, plant remains and soil (especially calcareous soil). It prefers open, dry and sunny habitats. Many of its stands are located in psammophilous and xerothermic grasslands.

Diploschistes muscorum is rarely recorded in the Polish lowlands; it is more common in the southern part of the country. It has been known from a few stands in the Nizina Wielkopolsko-Kujawska Lowland, mostly from its western part. In 2016 a new locality of Diploschistes muscorum was discovered. The new site is situated at Baranów (Wieruszów Upland) in the southern part of Wielkopolsko-Kujawska Lowland. The specimen has been collected from psammophilous grasslands; it has overgrown thalli of Cladonia sp. and soil. Associating lichen species include: Cladonia cervicornis subsp. verticillata (Hoffm.) Ahti, C. furcata (Huds.) Schrad., C. pyxidata (L.) Hoffm., C. subulata (L.) Weber ex F.H. Wigg. and Peltigera didactyla (With.) J.R. Laundon. 